\title{
Measurement of Fat-Free Mass in Infants
}

\author{
NIELS C. DE BRUIN, KLAAS R. WESTERTERP, HERMAN J. DEGENHART, AND \\ HENK K. A. VISSER \\ Department of Pediatrics, Erasmus University and University Hospital Rotterdam/Sophia Children's \\ Hospital, the Netherlands [N.C.d.B., H.J.D., H.K.A.V.] and Department of Human Biology, \\ Limburg University, Maastricht, the Netherlands [K.R.W.]
}

\begin{abstract}
Body composition data are important for adequate monitoring of growth and nutritional status in infants. ${ }^{18} \mathrm{O}$. Isotope dilution techniques $\left(\mathrm{ID}_{18-\mathrm{O}}\right)$ are widely used to estimate total body water (TBW) and calculate fat-free mass (FFM). A problem of isotope dilution is an underestimation of TBW by the extrapolation to $t$ $=0$ approach and an overestimation of TBW by the plateau approach. Using total body electrical conductivity (TOBEC) as the reference technique we validated the extrapolation approach by 149 measurements (boys, $n=76$; girls, $n=73$ ) in 50 healthy infants aged 1-12 mo. TOBEC-derived FFM and fat mass were in excellent agreement with Fomon's reference data. Strictly linear relationships with slopes not significantly different from one were found between FFM estimated by TOBEC (FFM ${ }_{\text {TO- }}$ BEC) and FFM estimated by $\mathrm{ID}_{18-\mathrm{O}}\left(\mathrm{FFM}_{18-\mathrm{O}}\right)(r=0.98$ and residual $\mathrm{SD}=0.29$ for boys, $r=0.98$ and residual $\mathrm{SD}=0.32$ for girls). $F F M_{18-O}$ was slightly but significantly lower than FFM $_{\text {TOBEC }}$, the difference being on average $0.18( \pm 0.24) \mathrm{kg}$ for girls and $0.08( \pm 0.21) \mathrm{kg}$ for boys (i.e. respectively $4( \pm 4.5) \%$ $(p<0.0001)$ and $1.5( \pm 3.9) \%(p=0.004)$ of FFM $\left._{\text {TOBEC }}\right)$. We conclude that $\mathrm{ID}_{18-\mathrm{O}}$ using the extrapolation to $t=0$ approach is

suitable for TBW and FFM estimations in groups of infants. Due to the considerable measurement error of ID $_{18 \text {-O }}$ (estimated at $\sim 6 \%$ ), individual $\mathrm{TBW}_{18-\mathrm{O}}$ and $\mathrm{FFM}_{18-\mathrm{O}}$ estimates should be considered with some caution. (Pediatr Res 38: 411-417, 1995)

\author{
Abbreviations \\ FFM $_{\text {TOBEC }}$, fat-free mass estimated by total body electrical \\ conductivity \\ FFM $_{18-0}$, fat-free mass estimated by ${ }^{18} \mathrm{O}$ isotope dilution \\ $\mathrm{ID}_{18-\mathrm{O}},{ }^{18} \mathrm{O}$ isotope dilution \\ $\mathbf{k}_{\mathbf{H}}$, elimination rate of ${ }^{2} \mathrm{H}\left(\right.$ as $\left.^{2} \mathrm{H}_{2} \mathrm{O}\right)$ \\ $\mathbf{N}_{\mathbf{H}}$, dilution space of ${ }^{2} \mathrm{H}$ (as $\left.{ }^{2} \mathrm{H}_{2} \mathrm{O}\right)$ \\ $\mathbf{N}_{\mathrm{O}}$, dilution space of ${ }^{18} \mathrm{O}\left(\right.$ as $\left.\mathrm{H}_{2}{ }^{18} \mathrm{O}\right)$ \\ TBF, total body fat \\ TBW, total body water \\ TBW $W_{\text {robec }}$, total body water estimated by total body \\ electrical conductivity \\ TBW $_{18-0}$, total body water estimated by ${ }^{18} \mathrm{O}$ isotope dilution \\ FFM $_{\text {anthro, }}$, anthropometry-derived fat-free mass
}

Body composition data are important for adequate monitoring of nutritional status and quality of growth, especially for preterm and young infants. However, for infants no "gold standard" body composition method exists and a limited number of data on infant body composition has been published. Traditional body composition methods used in infancy are anthropometry (1-4) and isotope dilution $(5,6)$. These methods are easy to perform and suitable for bedside and field studies. Although they have been extensively validated in adults and older children, the lack of a good reference method prohibited accurate validation in infants

Recently measurement of TOBEC has emerged as an accurate, precise and reproducible method for the estimation of

Received December 5, 1994; accepted April 11, 1995.

Manuscript dedicated to Professor H. K. A. Visser in honor of his retirement

Correspondence: N. C. de Bruin, M.D., Sophia Children's Hospital, Dr. Molewaterplein 60, 3015 GJ Rotterdam, The Netherlands.

Supported in part by the Sophia Foundation for Medical Research, Nutricia Research Laboratories, Trustfonds Foundation of the Erasmus University Rotterdam, University Hospital Rotterdam, and Foundation "De Drie Lichten" in The Netherlands.
FFM and TBF in infants (4, 7-11). Calibration against carcass analysis data of minipigs as well as assessment of precision of TOBEC has been performed (12). The validity of the minipig calibration equation for use in human infants has been proven in two ways. First, all reported TOBEC data for TBF of full-term infants throughout the first year of life $(4,7,13)$ are in excellent agreement with reference data on TBF, which had been calculated from the combination of TBW, total body potassium, and skinfold thickness measurements (14). Second, Fiorotto (8) showed that when the changes in the actual amount of TBF present in intrauterine life (measured by carcass analysis of human fetusses) and extrauterine life (measured by TOBEC during the first 4 mo of life) are plotted against age, the lines of the extra- and intrauterine period nicely coincide (with equal slopes) around the time of birth. Physiologic changes in hydration of the FFM during the process of FFM maturation in early life are accounted for by the calibration procedure (15). The method has been found to be resistant to changes in extracellular fluid volume (16), so physiologic 
changes in FFM hydration (i.e. water content of the FFM) will not seriously affect TOBEC outcome (10). A TOBEC measurement is rapid, safe, and easy to perform, and suitable for measurement of large numbers of infants. The instrument has been commercially available since 1989 . At present TOBEC is one of the most reliable methods to estimate infant body composition, but is not widely used, due to the relatively high price of a TOBEC instrument (approximately $\$ 45,000$ ) and the fact that the instrument is large, difficult to move, and therefore not suitable for field studies. However, its good reproducibility, precision, and accuracy justify the use of TOBEC as a reference method for, e.g. cross-validation studies against anthropometry and isotope dilution. Based on this fact we recently described a cross-validation against TOBEC of two known anthropometric methods for TBF and FFM estimation in infants (4).

It is known that isotope dilution either underestimates "true" TBW when calculated by the extrapolation to $t=0$ or overestimates TBW when calculated by the plateau approach (17). This is due, respectively, to the fact that the assumption of instantaneous mixing of the label is not valid (extrapolation approach) and that only urinary loss of label in the equilibration phase can be accounted for (plateau approach). Because the exact magnitude of these errors is unknown, we crossvalidated the extrapolation approach (based on two urine samples) against the TOBEC technique. The extrapolation approach is convenient for body composition studies and is often used in combination with energy expenditure studies using doubly labeled water. We assessed whether TOBEC and isotope dilution were strictly linearly related throughout the entire first year of life. Accuracy and precision, compared with TOBEC, of the isotope dilution-derived TBW and FFM estimates were determined, and gender- and age-related differences between methods were explored.

\section{METHODS}

Subjects. The present study was part of a prospective study on growth, body composition, and energy metabolism of breast-fed and formula-fed infants. Fifty infants were enrolled after written informed consent was obtained from their parents. All were healthy full-term Caucasian infants from healthy mothers and vaginally born without complications. Measurements were performed at the age of $1,2,4,8$, and $12 \mathrm{mo}$. Isotope dilution measurements $(n=175)$ were performed as part of an (doubly labeled water) energy expenditure experiment. The study protocol was approved by the ethical review board of the Medical Faculty and University Hospital of the Erasmus University Rotterdam.

Anthropometry. Infants were weighed naked on an electronic baby scale (Instru Vaaka Oy, Finland) to the nearest $1 \mathrm{~g}$ $(0-3 \mathrm{~kg}$ body weight), $2 \mathrm{~g}(3-6 \mathrm{~kg})$, or $5 \mathrm{~g}(6-10 \mathrm{~kg})$ at the time of the TOBEC measurement and at the end of the isotope dilution period (d 9). Recumbent length and head circumference were measured according to Lohman et al. (18).

TOBEC. Body temperature affects TOBEC outcome (10), therefore no infants with apparent or anamnestic fever were measured. Infants were not fed for at least $2 \mathrm{~h}$ preceding the measurement. To prevent cooling and to ensure geometric homogeneity between infants with respect to the introduction of the conductive mass into the electromagnetic field, infants were undressed and carefully swaddled in a large blanket, while care was taken that limbs were not flexed and did not touch each other or the trunk. Infants were placed on their back on the sled of the instrument. A pacifier was allowed when necessary. One TOBEC reading took approximately $10 \mathrm{~s}$. A complete TOBEC measurement consisted of 10 reliable 10 -s readings which were averaged for calculation of $\mathrm{FFM}_{\mathrm{TOBEC}}$. When the infant had urinated, it was swaddled again in a dry blanket and remeasured. Movement or crying during a reading was also a reason for remeasuring the infant.

Instrument specification and safety, measurement procedure, and FFM calculation from raw TOBEC data have been described earlier $(4,10,19)$. TBF and FFM were calculated from raw TOBEC data using a (theoretically deduced) transformed TOBEC value (T\#) (15). The calibration equation relating $\mathrm{FFM}_{\mathrm{TOBEC}}$ to T\#, derived from minipig data and described in detail before (12), was: $\mathrm{FFM}_{\mathrm{TOBEC}}=0.0264 \times \mathrm{T} \#-0.0213$. Precision for an individual measurement was $0.154 \mathrm{~kg}$ of FFM (i.e. the $95 \%$ prediction interval of the minipig-calibration curve), which is consistent with an uncertainty in the FFM estimate of less than $5 \%$ in infants with an above $\sim 3-\mathrm{kg}$ FFM (12). Intra-measurement variation was $<0.5 \%$, and long term instrument drift, measured over an $2-y$ period, was $0.5 \%$ as measured with a cylindrical reference phantom with known conductivity index and supplied by the manufacturer (12).

Isotope dilution. Directly after the TOBEC measurement, TBW was determined by standard isotope dilution techniques using $2 \mathrm{~mL} / \mathrm{kg}$ body weight of water enriched with $5 \%{ }^{2} \mathrm{H}$ and $10 \%{ }^{18} \mathrm{O}$. After collecting a baseline urine sample with a disposable adhesive collection bag, the ${ }^{2} \mathrm{H}_{2}{ }^{18} \mathrm{O}$ solution was administered orally by means of a bottle with a known amount of formula or dextrose added to the mixture. In a few infants some fluid was spoiled, which was collected, weighed, and subtracted from the dose. Bottles were rinsed with $\sim 20 \mathrm{~mL}$ of formula or dextrose, which was also consumed by the infant. A postdose urine sample was collected after at least $5 \mathrm{~h}$ and two urine voids. A second urine sample was collected at d 9. Samples were collected with new disposable collection bags at home by the mother. Urine samples were transferred to glass jars immediately after collection and stored at $-25^{\circ} \mathrm{C}$. Exact times of the urine collections were noted by the mother. No further intake or excretion of water/label between time of dosing and first postdose urine sampling was recorded. Infants were not weighed at the time of the postdose urine sampling. The time zero intercept approach, based on more than one postdose data point per individual, allows for continuous intake and excretion of water. Because this model assumes instant mixing of label in the body water pool, which is obviously untrue, the only problem is the fluid intake during the process of mixing of label with the body water pool. Based on plasmaisotope data from Trowbridge et al. (5) and Whyte et al. (20), we assumed for infants this would not exceed $1 \mathrm{~h}$. The normal feeding pattern of the infants therefore was allowed to be continued $1 \mathrm{~h}$ after dosing. Stabilizing of urinary tracer output has been shown to lag behind plasma equilibration for at least 
2-3 h (5), so start of postdose urine sampling was kept at $>5$ $h$ postdose.

Isotope analyses of the initial ${ }^{2} \mathrm{H}_{2}{ }^{18} \mathrm{O}$ solutions and urine samples were performed in duplicate using an isotope ratio mass spectrometer (Aqua-SIRA, VG Isogas, Cheshire, UK) as described earlier (21). Briefly, 5- $\mu \mathrm{L}$ urine samples were introduced into the heated inlet system of the mass spectrometer with an autoinjector. After evaporation the water vapor flows directly to one analyzer for ${ }^{18} \mathrm{O}$ measurement and through a uranium furnace into a second analyzer for ${ }^{2} \mathrm{H}$ measurement after conversion to ${ }^{2} \mathrm{H}_{2}$ and $\mathrm{H}_{2}$. The analytical precision was $0.2 \mathrm{ppm}$ for ${ }^{2} \mathrm{H}$ and $0.4 \mathrm{ppm}$ for ${ }^{18} \mathrm{O}$.

Urinary tracer concentrations were corrected for additional isotope dilution caused by change of the body water compartment during the $8 \mathrm{~d}$ of the experiment, as well as for the timing error of each urine sample caused by mixing of urine with decreasing concentrations of label in the bladder between two subsequent voids. The study protocol did not account for timing of the previous void (i.e. the void before the actual urine collection), therefore only a first order correction could be applied for this phenomenon. Because an average voiding interval of $2 \mathrm{~h}$ as observed in neonates is reasonable as a maximal frequency throughout the first year of life, $1 \mathrm{~h}$ was subtracted from the time of collection of each urine sample.

${ }^{2} \mathrm{H}$ pool size $\left(\mathrm{N}_{\mathrm{H}}\right)$ and ${ }^{18} \mathrm{O}$ pool size $\left(\mathrm{N}_{\mathrm{O}}\right)$ were calculated by extrapolation to $t=0$ (22). As both isotopes were administered concomitantly, the ratio $\mathrm{N}_{\mathrm{H}} / \mathrm{N}_{\mathrm{O}}$ is very narrowly defined and was used as a measure for the reliability of the urine sample. Data were excluded when $\mathrm{N}_{\mathrm{H}} / \mathrm{N}_{\mathrm{O}}$ ratio was beyond $3 \mathrm{SD}$ from mean $\mathrm{N}_{\mathrm{H}} / \mathrm{N}_{\mathrm{O}}$. This ratio is normally distributed (results not shown), resulting in a loss of $<1 \%$ of normal data that will be rejected. Nineteen data points were excluded on this ground. An additional seven measurements were excluded on the basis of the fact that not all spoiled tracer could be collected (six cases) and of unclear notation of urine collection times (one case). $\mathrm{TBW}_{18-\mathrm{O}}$ was calculated as $\mathrm{N}_{\mathrm{O}} / 1.01$, where 1.01 is a correction for rapidly exchangeable nonaqueous oxygen (23).

In early life the hydration of the FFM compartment rapidly changes with age. To convert TBW into FFM, we used data on changes in FFM hydration in infants by gender published by Fomon et al. (14).
Statistical analysis. Determination of linearity and correlation between methods was calculated using the statistical technique to assess linear regression from combined longitudinal data as described by Draper and Smith (24). Comparison of FFM $_{\text {TOBEC }}$ and FFM $_{18-O}$ was performed by a paired $t$ test. Estimation of agreement was performed using the method as proposed by Bland and Altman (25). An effect was assumed to be significant at $p<0.05$. Unless stated differently data are expressed as mean $( \pm \mathrm{SD})$.

\section{RESULTS}

Subject characteristics and body composition. Subject characteristics are shown by age and gender in Table 1. Weight, length and head circumference were in accordance with Dutch reference data (26). Significant differences between sexes were observed for body weight, length, and head circumference.

Body composition estimations by TOBEC are summarized by age and gender in Table 2. Mean TOBEC background reading was $38( \pm 4)$ TOBEC units. Room temperature and relative room humidity at the time of the TOBEC measurements were, respectively, $22.7( \pm 0.9)^{\circ} \mathrm{C}$ and $41.6( \pm 6.6) \%$. Intra-measurement uncertainty (coefficient of variation of the consecutive 10-s TOBEC readings) averaged $1.3 \%$ (range $0.1-4.4 \%$ ); only two cases showed a coefficient of variation $>$ $3 \%$, which shows the excellent reproducibility of TOBEC measurements. A significant difference between sexes was observed for FFM TOBEC $_{\text {. }}$

Isotope dilution data are summarized in Table 2. Mean $\mathrm{N}_{\mathrm{H}} / \mathrm{N}_{\mathrm{O}}$ was $1.028(\mathrm{SD}=0.006 ; \mathrm{SEM}=0.001)$. TBW calculated from ${ }^{18} \mathrm{O}$ dilution $\left(\mathrm{TBW}_{18-\mathrm{O}}\right)$ was on average $5( \pm 25) \mathrm{mL}$ higher than TBW calculated from ${ }^{2} \mathrm{H}$ dilution (not significant). Significant differences between sexes were observed (see Table 2) for $\mathrm{FFM}_{18-\mathrm{O}}, \mathrm{TBW}_{18-\mathrm{O}}(\mathrm{kg})$ and $\mathrm{TBW}_{18-\mathrm{O}}(\%)$.

Comparison of TOBEC and isotope dilution. Regression $(23,24)$ of $\mathrm{FFM}_{\mathrm{TOBEC}}(Y)$ against $\mathrm{FFM}_{18-\mathrm{O}}(X)$ revealed:

1a. All data: $Y=-0.07( \pm 0.12)+0.98( \pm 0.02) X(r=$ 0.98 ; residual $\mathrm{SD}=0.29$ )

Ib. Boys: $Y=-0.08( \pm 0.15)+0.99( \pm 0.03) X(r=0.99$; residual $\mathrm{SD}=0.27$ )

Table 1. Subject characteristics

\begin{tabular}{|c|c|c|c|c|c|c|}
\hline \multirow{2}{*}{$\begin{array}{l}\text { Age } \\
\text { (mo) }\end{array}$} & \multirow[b]{2}{*}{$n$} & \multirow[b]{2}{*}{ Age (d) } & \multicolumn{2}{|c|}{ Body weight } & \multirow[b]{2}{*}{ Length $(\mathrm{cm})$} & \multirow[b]{2}{*}{ Head circumference $(\mathrm{cm})$} \\
\hline & & & d $1(\mathrm{~kg})$ & d $8(\mathrm{~kg})$ & & \\
\hline \multicolumn{7}{|l|}{ Boys } \\
\hline 1 & 20 & $36(3)$ & $4.56(0.46)^{b}$ & $4.89(0.52)^{b}$ & $55.9(2.3)$ & $38.1(1.0)^{a}$ \\
\hline 2 & 19 & $66(5)$ & $5.49(0.57)^{a}$ & $5.96(1.25)^{a}$ & $60.0(2.3)^{a}$ & $39.7(1.1)^{a}$ \\
\hline 4 & 18 & $124(4)$ & $6.66(0.83)$ & $6.80(0.80)$ & $65.5(2.0)^{b}$ & $41.7(1.1)^{b}$ \\
\hline 8 & 14 & $244(9)$ & $8.46(0.36)$ & $8.47(0.80)$ & $71.7(2.4)$ & $44.6(1.1)$ \\
\hline 12 & 8 & $371(7)$ & $10.51(0.63)^{a}$ & $10.57(0.61)^{a}$ & $78.9(2.0)^{a}$ & $46.7(1.3)$ \\
\hline \multicolumn{7}{|l|}{ Girls } \\
\hline 1 & 18 & $33(4)$ & $4.19(0.42)$ & $4.42(0.42)$ & $55.1(2.3)$ & $37.1(1.2)$ \\
\hline 2 & 16 & $65(5)$ & $4.85(0.48)$ & $5.13(0.50)$ & $58.0(1.7)$ & $38.6(1.0)$ \\
\hline 4 & 18 & $123(7)$ & $6.13(0.66)$ & $6.30(0.67)$ & $63.2(2.3)$ & $40.9(1.1)$ \\
\hline 8 & 13 & $248(10)$ & $8.19(0.74)$ & $8.35(0.74)$ & $70.8(2.6)$ & $44.1(1.1)$ \\
\hline 12 & 9 & $369(11)$ & $9.49(0.60)$ & $9.47(0.65)$ & $75.6(2.0)$ & $45.9(1.0)$ \\
\hline
\end{tabular}

Mean (SD). Difference between sexes (Mann-Whitney $U$ test): ${ }^{a} p<0.01 ;{ }^{b} 0.01<p<0.05$. 
Table 2. TOBEC and isotope dilution results

\begin{tabular}{|c|c|c|c|c|c|c|c|c|}
\hline Age (mo) & $n$ & $\mathrm{TBF}_{\text {TOBEC }}(\mathrm{kg})$ & $\mathrm{TBF}_{\text {TOBEC }}(\%)$ & $\mathrm{FFM}_{\text {TOBEC }}(\mathrm{kg})$ & $\mathrm{TBW}_{18-\mathrm{O}}(\%)$ & $\mathrm{TBW}_{18-\mathrm{O}}(\mathrm{kg})$ & $\mathrm{FFM}_{18-\mathrm{O}}(\mathrm{kg})$ & $\mathrm{N}_{\mathrm{H}} / \mathrm{H}_{\mathrm{O}}$ ratio \\
\hline \multicolumn{9}{|l|}{ Boys } \\
\hline 1 & 20 & $0.69(0.22)$ & $15.0(3.9)$ & $3.87(0.35)$ & $66.7(3.4)$ & $3.04(0.30)^{c}$ & $3.78(0.38)$ & $1.025(0.005)$ \\
\hline 2 & 19 & $1.09(0.23)$ & $19.7(3.6)$ & $4.40(0.38)^{b}$ & $62.9(3.0)$ & $3.43(0.31)^{a}$ & $4.32(0.39)^{a *}$ & $1.028(0.007)$ \\
\hline 4 & 18 & $1.65(0.43)$ & $22.4(4.0)$ & $5.01(0.44)^{b}$ & $59.7(3.9)$ & $3.99(0.28)^{b}$ & $4.97(0.36)^{11}$ & $1.030(0.006)$ \\
\hline 8 & 14 & $2.25(0.26)$ & $26.6(2.4)$ & $6.21(0.26)$ & $58.3(2.3)^{b}$ & $4.93(0.26)^{b}$ & $6.19(0.33)^{b}$ & $1.028(0.006)$ \\
\hline 12 & 8 & $2.56(0.44)$ & $24.3(3.1)$ & $7.96(0.36)^{b}$ & $58.7(4.0)$ & $6.15(0.19)^{b}$ & $7.80(0.23)^{b}$ & $1.030(0.008)$ \\
\hline Mean (SD) & 76 & $1.47(0.73)$ & $21.2(5.5)$ & $5.08(1.32)^{c}$ & $61.9(4.6)^{b}$ & $3.99(1.02)^{b}$ & $5.00(1.31)^{\prime \prime}$ & $1.028(0.006)$ \\
\hline \multicolumn{9}{|l|}{ Girls } \\
\hline 1 & 18 & $0.59(0.12)$ & $14.1(2.3)$ & $3.60(0.36)$ & $66.4(3.1)$ & $2.78(0.30)$ & $3.46(0.37)^{* *}$ & $1.028(0.004)$ \\
\hline 2 & 16 & $0.97(0.22)$ & $19.8(3.5)$ & $3.88(0.33)$ & $60.5(3.3)$ & $2.93(0.26)$ & $3.68(0.33)^{* * *}$ & $1.028(0.004)$ \\
\hline 4 & 18 & $1.58(0.32)$ & $25.6(3.5)$ & $4.55(0.44)$ & $58.1(4.5)$ & $3.55(0.42)$ & $4.44(0.51)^{*}$ & $1.029(0.007)$ \\
\hline 8 & 13 & $2.22(0.31)$ & $27.1(2.9)$ & $5.97(0.56)$ & $55.3(2.7)$ & $4.50(0.32)$ & $5.64(0.41)^{* *}$ & $1.028(0.007)$ \\
\hline 12 & 9 & $2.56(0.30)$ & $27.0(2.8)$ & $6.93(0.52)$ & $56.2(3.2)$ & $5.34(0.56)$ & $6.77(0.71)$ & $1.030(0.003)$ \\
\hline Mean (SD) & 73 & $1.43(0.75)$ & $21.9(6.0)$ & $4.70(1.24)$ & $59.9(5.4)$ & $3.60(0.95)$ & $4.52(1.22)$ & $1.028(0.006)$ \\
\hline \multicolumn{9}{|l|}{ All data } \\
\hline Mean (SD) & 1.49 & $1.45(0.75)$ & $21.5(5.8)$ & $4.89(1.29)$ & $60.9(5.1)$ & $3.80(1.01)$ & $4.76(1.28)$ & $1.028(0.006)$ \\
\hline
\end{tabular}

Mean (SD). Difference between sexes (Mann-Whitney- $U$ test): " $p<0.001,{ }^{b} 0.001<p<0.01,{ }^{c} 0.01<p<0.05$. Difference between FFM $\mathrm{TOBEC}_{\text {and }}$ $\mathrm{FFM}_{18-\mathrm{O}}$ (Wilcoxon matched-pairs signed-ranks test): ${ }^{* *} p<0.001,{ }^{* *} 0.001<p<0.01,{ }^{*} 0.01<p<0.05$.

Ic. Girls: $Y=-0.05( \pm 0.18)+0.97( \pm 0.04) X(r=0.98$; residual $\mathrm{SD}=0.32$ ).

Slopes were not significantly different from one and intercepts were not significantly different from zero.

Figure 1 shows a graphical representation of the relation between $\mathrm{FFM}_{\text {TOBEC }}$ and $\mathrm{FFM}_{18 \text {-O }}$ by gender. After correction for the covariable age no significant correlation was found between absolute residual errors of the regression of
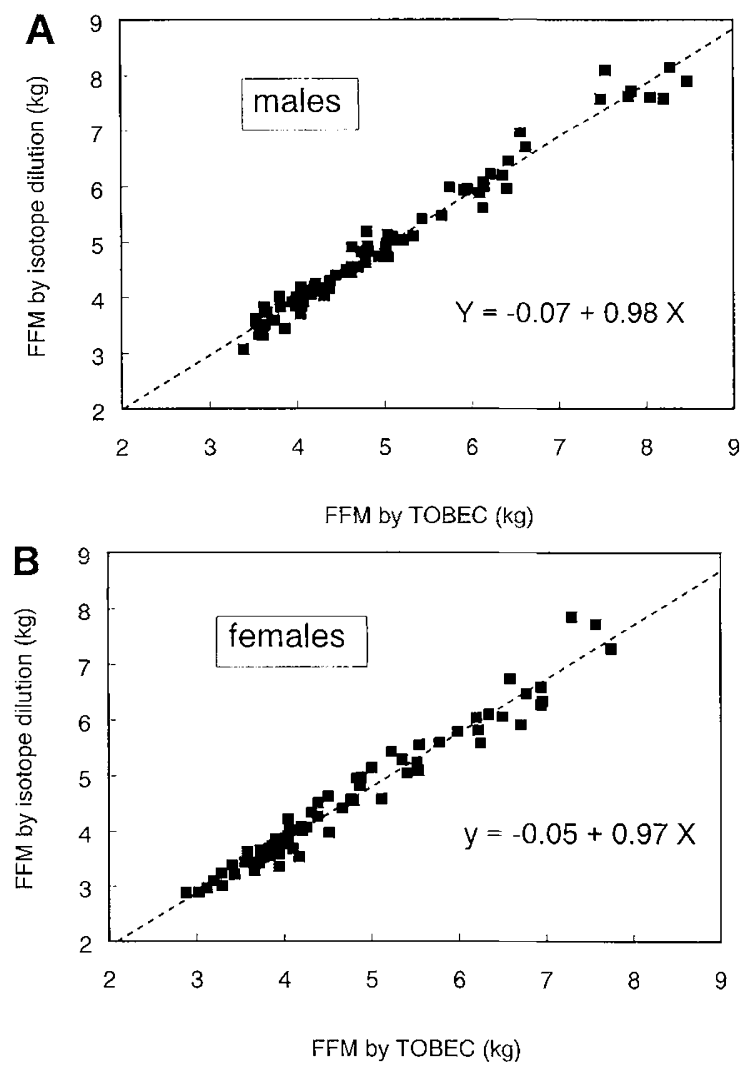

Figure 1. $\mathrm{FFM}_{\mathrm{TOBFC}}(\mathrm{kg})$ against $\mathrm{FFM}_{18-\mathrm{O}}(\mathrm{kg})$ by gender. Dotted line represents the calculated regression equation. $A$, Boys; $B$, girls.
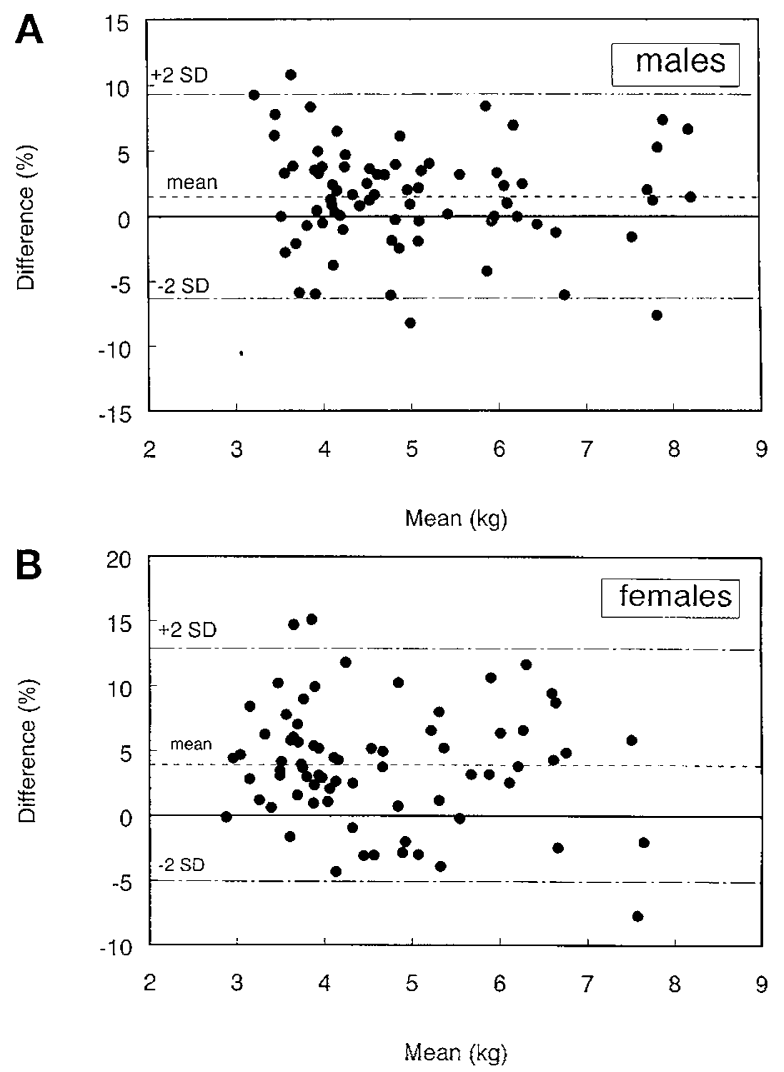

Figure 2. Difference against mean for $\mathrm{FFM}_{\mathrm{TOBEC}}(\mathrm{kg})$ and $\mathrm{FFM}_{18-\mathrm{O}}(\mathrm{kg})$ by gender. Differences are expressed as percent of $\mathrm{FFM}_{\text {TOBEC }}$ A, boys: mean difference $=1.5 \%$. Limits of agreement $( \pm 2 \mathrm{SD})=-6.3 \%$ to $9.3 \%$. SE of limits of agreement $=0.77 \%(25)$. $B$, Girls: mean difference $=4 \%$. Limits of agreement $( \pm 2 \mathrm{SD})=-5.1 \%$ to $12.9 \%$. SE of limits of agreement $=0.91 \%$ (25).

$\mathrm{FFM}_{\mathrm{TOBEC}}$ and $\mathrm{FFM}_{18-\mathrm{O}}$ and potential confounding parameters as e.g. weight, length, and $\mathrm{N}_{\mathrm{H}} / \mathrm{N}_{\mathrm{O}}$ ratio.

In Figure 2 the difference of the values obtained using both methods is plotted against their averaged value. The limits of agreement or $95 \%$ confidence limits for an individual estimate (25) is $8-9 \%$ for both sexes and not significantly different with 
age. Although the regression slopes 1a through 1c were not significantly different from one and intercepts not significantly different from zero, a paired $t$ test showed that TOBEC resulted in significantly higher values of FFM than isotope dilution, both in boys $(p=0.0004)$ and girls $(p<0.0001)$. Calculated separately by age and gender, $\mathrm{FFM}_{\mathrm{TOBEC}}$ was significantly lower than FFM 18 -o in girls for all age groups except at $12 \mathrm{mo}$ of age, whereas in boys only at 2 mo of age a significant difference between isotope dilution and TOBEC was found $(p=0.016)$ (see also Table 2). Table 3 shows the differences between $\mathrm{FFM}_{\text {TOBEC }}$ and $\mathrm{FFM}_{18-\mathrm{O}}$ by age and gender (in $\mathrm{kg}$ and as percentage of $\left.F \mathrm{M}_{\mathrm{TOBEC}}\right)$. On average the difference in FFM between both methods was $0.13( \pm 0.23) \mathrm{kg}$ (i.e. $2.7 \%$ of $\left.F_{F M} M_{T O B E C}\right)$. Values for the difference between TOBEC and isotope dilution differed significantly by gender $(p=0.004)$ : on average $0.08( \pm 0.21) \mathrm{kg}$ for boys and $0.18( \pm 0.24) \mathrm{kg}$ for girls (which is consistent with, respectively, 1.5 and $4 \%$ of $\left.\mathrm{FFM}_{\text {TOBEC }}\right)$. For $\mathrm{TBW}$ the difference between $\mathrm{TBW}_{\mathrm{TOBEC}}$ and $\mathrm{TBW}_{18-\mathrm{O}}$ averaged 0.06 and $0.14 \mathrm{~kg}$ (which is also consistent with 1.5 and $4 \%$ of $\mathrm{TBW}_{\text {TOBEC}}$ ). All differences between isotope dilution and TOBEC as calculated by gender were not significantly related to age.

\section{DISCUSSION}

The majority of data on TBW in infants have been derived in the past from ${ }^{2} \mathrm{H}$ dilution by the traditional plateau approach, as formerly used in adults (short equilibration time) and with plasma or urinary ${ }^{2} \mathrm{H}$ concentrations measured by the falling drop method or infrared spectroscopy. More detailed data on the isotope dilution methodology in infants, as e.g. plasma and urine equilibration time in infants, have been published more recently $(5,20)$. Until now very few authors reported data on infant TBW using ${ }^{18} \mathrm{O}$ dilution, especially for older infants. More TBW and FFM data from isotope dilution will certainly become available in the near future, as the doubly labeled water method used for estimation of energy expenditure has recently been validated for use in infants and TBW and FFM are among the outcome parameters (27-29).

Because body weight, TBF $\mathrm{TOBEC}_{\text {and }} \mathrm{FFM}_{\text {TOBEC }}$ of the present study were in accordance with reference data (14), the

Table 3. Differences between FFM

\begin{tabular}{lll} 
& \multicolumn{3}{c}{ gender } & \\
\hline (FFM & Male & Female \\
\hline Difference $(\mathrm{kg}):$ & & \\
1 mo & & \\
2 mo & $0.09(0.18)^{*}$ & $0.13(0.12)$ \\
4 mo & $0.08(0.13)$ & $0.21(0.19)$ \\
8 mo & $0.06(0.20)$ & $0.11(0.22)$ \\
12 mo & $0.02(0.21)$ & $0.32(0.29)$ \\
Mean (SD) & $0.16(0.39)$ & $0.17(0.38)$ \\
Difference (\% FFM TOBEC $):_{1 \text { mo }}$ & $0.08(0.21)$ & $0.18(0.24)$ \\
2 mo & & \\
4 mo & $2.2(4.8)$ & $3.7(3.3)$ \\
8 mo & $1.8(2.9)$ & $5.2(4.7)$ \\
12 mo & $1.1(3.8)$ & $2.6(4.8)$ \\
Mean (SD) & $0.4(3.3)$ & $5.2(4.5)$ \\
\hline
\end{tabular}

* Mean (SD). Results did not differ significantly between age groups. data suggest that $\mathrm{H}_{2}{ }^{18} \mathrm{O}$ dilution underestimates FFM, at least when using the extrapolation approach (Fomon et al. presented only the mean values per age group, without any indication on biological and instrumental scatter. We assumed a parameter to be "in accordance" when the reference data point was within 1 $\mathrm{SD}$ of the present study parameter). Underestimation is to be expected, as one of the basic assumptions of the extrapolation approach is instantaneous mixing of the label with the body water pool after dose administration. Mean time of urine sampling in our study was $10.4( \pm 6.3) \mathrm{h}$ after dosing. Average water loss between the time of dosing and first urine sample can be estimated from the elimination rate of ${ }^{2} \mathrm{H}$. The mean elimination rate of ${ }^{2} \mathrm{H}\left(\mathrm{k}_{\mathrm{H}}\right)$ was $0.225( \pm 0.045)$, which equals a water loss $\sim 35 \mathrm{~mL} / \mathrm{h}$. It takes approximately $5 \mathrm{~h}$ before label has completely mixed with the body water pool (5). During this time water intake, water output, and loss of label with water output are not yet in equilibrium, each of which factors can result in errors. During this time on average $175 \mathrm{~mL}$ of water are lost with an unknown amount of tracer. This observation shows that water and tracer loss in the early equilibrium phase on its own will account for most if not all of the underestimation of TBW by ${ }^{18} \mathrm{O}$ dilution.

As Coward (17) has already pointed out, the plateau as well as the extrapolation approach rest upon basic assumptions which cause respectively an overestimation and an underestimation of TBW. Our $\mathrm{TBW}_{18-\mathrm{O}}$ data were comparable with those of Davies and Lucas (3), who also used the extrapolation approach for isotope dilution. Fjeld et al. (6) measured infants between 3 and $30 \mathrm{mo}$ (on average $13 \mathrm{mo}$ ) using the plateau approach. They reported mean TBW values for the study groups which were, when back-extrapolated to 12 mo of age, slightly higher then our data. We found one report supplying raw data on both the extrapolation and the plateau approach (1). The authors measured TBW in 15 infants aged $0-3$ mo. Although a small number of infants was measured, a genderrelated difference between plateau and extrapolation can be calculated from the raw data, averaging, respectively, 0.05 $( \pm 0.26) \mathrm{kg}$ and $0.14( \pm 0.15) \mathrm{kg}$ for boys and girls. This difference between plateau and extrapolation almost fully accounts for the discrepancy between TOBEC and isotope dilution found in the present study.

It should be noted that TOBEC measures FFM, which is converted into TBW, whereas isotope dilution measures TBW, which is converted into FFM. In the present study the same FFM hydration constants as published by Fomon et al. (14) have been used for both calculations. The dependence upon gender in the difference between TOBEC and isotope dilution (respectively, 1.5 and 4\% FFM) is not attributable to these FFM hydration factors, for it was also observed in the raw $\mathrm{TBW}_{18-\mathrm{O}}$ data. A possible explanation for this difference between boys and girls could have been a difference in water turnover; however, $\mathrm{k}_{\mathrm{H}}$ values were not significantly different between boys and girls. Another explanation for the difference might be a lesser miction frequency in girls. More time between subsequent voids will result in an increased error in the "real" sample time related to the concentration of label in a certain sample. It is not likely that urine collection itself, which is more difficult to perform in girls than in boys, will be the 
source of the difference between boys and girls, for this would most likely also have affected the $N_{H} / N_{O}$ ratio. It is also not likely that gender differences in FFM density and hence in conductivity would have affected the TOBEC signal and so produced an artificial difference in FFM between boys and girls, for it has been reported that small changes in FFM hydration and density do no affect TOBEC outcome $(8,10)$, whereas we showed that TOBEC body composition data were in excellent agreement with former reports and published reference data. A final explanation might be a difference in feeding mode between both sexes. The study group existed of infants which were exclusively breast-fed or formula-fed for at least $4 \mathrm{mo}$. It has been postulated formula feeding results in a more pronounced growth of the FFM compartment and formula has a higher renal solute load, which both may result in a difference in labeled water clearance. However, although a significant difference in feeding mode was present (boys: $35 \%$ breast-fed and 65\% formula-fed; and girls: $56 \%$ breast-fed and $44 \%$ formula-fed, $p=0.01$ by $\chi^{2}$ test) the difference between $\mathrm{FFM}_{\text {TOBEC }}$ and FFM 18 -O (as shown in Figure 2, $A$ and $B$, and expressed as a percentage of $\mathrm{FFM}_{\text {TOBEC }}$ ) was not significantly correlated to feeding mode and not significantly different between feeding mode ( $p=0.6$, by analysis of variance), neither for girls nor for boys. The present data therefore do not support the idea that mode of feeding has an effect on the rate of excretion of labeled water.

The present study shows that, besides a significant underestimation of $4 \%$ in TBW and FFM in girls and $1.5 \%$ in TBW and FFM in boys, isotope dilution results are linearly related to TOBEC and are on average not significantly different from unity. Therefore, isotope diiution is suitable for TBW estimations and subsequent calculation of FFM in groups of infants. However, one should exert caution in using isotope dilution data for individual estimations of TBW, due to the relatively large measurement error (maximally $8-9 \%$ for an individual estimate). Also, isotope dilution has no ability to account for biologic scatter in FFM hydration, as fixed values for FFM hydration are used to convert TBW into FFM. Differences in FFM hydration will be averaged out when groups of infants are described, but will significantly affect an individual estimate of FFM. TOBEC calibration studies using minipig carcass analysis data show a precision of an individual measurement of $\sim 0.15 \mathrm{~kg}(12)$. The residual SD of the regression of FFM $\mathrm{FOBEC}_{\text {TO }}$ and $\mathrm{FFM}_{18 \text {-O }}$ in the present study on average was $0.23 \mathrm{~kg}$, which suggests that isotope dilution is less precise than TOBEC. One could argue, however, that the precision of carcass studies cannot be extrapolated to infants. Precision of FFM $_{\text {anthro }}$ has been reported to be approximately $0.35 \mathrm{~kg}$ (4). Because anthropometry data were also available in the present study, $\mathrm{FFM}_{18-\mathrm{O}}$ was regressed (24) against $\mathrm{FFM}_{\text {anthro, }}$ which revealed a correlation of $r=0.98$ and residual $\mathrm{SD}=0.40 \mathrm{~kg}$ for boys and $r=0.97$ and residual $\mathrm{SD}=0.43 \mathrm{~kg}$ for girls. The increase in residual SD compared with regression against FFM $_{\text {TOBEC }}$ confirms the superior precision of TOBEC compared with anthropometry and isotope dilution. Moreover, Figure 2 shows that, although the average difference between methods is small (respectively, 1.5 and $4 \%$ for boys and girls) the limits of agreement (i.e. $2 \mathrm{SD}$ of the difference between methods) are considerable, being approximately $8-9 \%$ for both sexes. This error results from both the TOBEC as well as the isotope dilution technique. An approximation of the amount of error arising from the isotope dilution technique can be derived as follows. The limits of agreement (i.e. $2 \mathrm{SD}$ ) of the difference between $\mathrm{FFM}_{\mathrm{TOBEC}}$ and $\mathrm{FFM}_{18-\mathrm{O}}$ were $\sim 400 \mathrm{~g}$. Assuming that the measurement error of anesthetized living minipigs approximates that of carefully swaddled infants, the TOBEC technique exerts an error (expressed here as $2 \mathrm{SD}$ ) of $\sim 150 \mathrm{~g}$. This shows that the isotope dilution technique must exert an additional error in the order of $250 \mathrm{~g}$, which is almost twice as much as the TOBEC technique and will approximate $6 \%$. Beside this, one should be even more cautious when FFM $_{18-0}$ is used for calculation of fat mass. In a child with e.g. a 4-kg FFM and 1-kg fat mass, an error of $\sim 6 \%$ in FFM results in an error of $\sim 25 \%$ in fat mass.

A potential source of error in the estimation of ${ }^{2} \mathrm{H}$ and ${ }^{18} \mathrm{O}$ pool sizes, which to our knowledge has never been accounted for, is the mixing of urine with decreasing concentrations of label in the bladder between two subsequent voids. Inherent to the bladder's function to store e.g. hypertonic fluid, urine water is not in direct equilibrium with TBW and thus the bladder cannot be a direct part of the TBW pool. Assuming that urine was collected at $t_{2}$ (with the previous void at $t_{1}$ ), the concentration of tracer in this sample in any calculation of TBW or $\mathrm{CO}_{2}$ production should not be related to $t_{2}$ but to $1 / 2\left(t_{1}+t_{2}\right)$. To roughly estimate the error due to this phenomenon, we recalculated $\mathrm{TBW}_{18 \text {-o }}$ while subtracting a fixed time value from the time of collecting the first and the second postdose sample. A subtraction of a minimum of $1 \mathrm{~h}$ was based on an assumed average miction interval of approximately $2 \mathrm{~h}$ as found in newborns. This value might well be a valid upper limit of voiding frequency, for all infants were not yet tidy at this time. Subtraction of $1 \mathrm{~h}$ through $2.5 \mathrm{~h}$ from the second postdose sample at $\mathrm{d} 9$ had no significant effect on $\mathrm{TBW}_{18-\mathrm{O}}$ (on average $<2 \mathrm{~mL}$ ) whereas the average effect on the first sample was $\sim 45 \mathrm{~mL}$ for a 1 -h subtraction, $65 \mathrm{~mL}$ for $1.5 \mathrm{~h}, 85 \mathrm{~mL}$ for $2 \mathrm{~h}$, and $110 \mathrm{~mL}$ when subtracting $2.5 \mathrm{~h}$ (i.e. $5 \mathrm{~h}$ between voids) from the sampling time. It was not possible to individually correct our data for this phenomenon for no accurate data on time of previous urine voids were available.

Although the literature is not consistent about the value for FFM hydration at birth (values ranging from $80-84 \%$ TBW have been reported) (30-32) and hydration factors during the first year of life have only once been estimated indirectly from deuterium dilution by the (obsolete) "falling drop method" and by whole body ${ }^{40} \mathrm{~K}$ counting (14), these uncertainties do not account for the observed discrepancy between $\mathrm{FFM}_{\mathrm{TOBEC}}$ and FFM $_{18-0}$. On average the difference between TOBEC and isotope dilution was a $0.13-\mathrm{kg}$ FFM. To account for this difference the FFM hydration at birth should become $\sim 75 \%$, whereas carcass data show FFM hydration factors of $80-84 \%$ (30-32). This example shows that, although true FFM hydration in infants is not well known, the discrepancy between $\mathrm{FFM}_{\mathrm{TOBEC}}$ and $\mathrm{FFM}_{18-\mathrm{O}}$ cannot be caused by FFM hydration factors.

A significant difference between $\mathrm{FFM}_{\mathrm{TOBEC}}$ and $\mathrm{FFM}_{18-\mathrm{O}}$ was observed, although the regression slopes of these param- 
eters showed no significant difference from unity. This paradox can be explained by the magnitude of the (relatively small) difference $[\sim 0.13( \pm 0.23) \mathrm{kg}]$ between both methods compared with the large absolute FFM values $(\sim 5 \mathrm{~kg})$. A paired $t$ test compares differences between methods versus zero and is sensitive to small changes, whereas a regression is based upon the values themselves and is therefore more robust to small changes. A large scatter therefore causes an initially significant but relatively small difference between methods, as found in the present study, to disappear when the values of these parameters are regressed. This phenomenon also shows that an important feature of the present study is the disclosure of the random error in the isotope dilution technique and a relatively small systematic difference between methods.

Summarizing, it can be concluded that FFM estimations by TOBEC and isotope dilution, although based on widely divergent principles, are strictly linearly related over the entire first year of life. A small but significant underestimation of $\mathrm{TBW}_{\text {TOBEC }}$ and $\mathrm{FFM}_{\text {TOBEC }}$ by isotope dilution was found which averaged $1.5 \%( \pm 3.9)$ for boys and $4 \%( \pm 4.5)$ for girls. Energy expenditure studies using doubly labeled water, as a "by-product" also allow for TBW and FFM estimations. Because of its moderate precision but relatively good accuracy, the isotope dilution technique is suitable for TBW and FFM estimations in groups but one should exert caution in individual estimates. Isotope dilution is suitable for body composition measurements in e.g. bedside and field studies.

Acknowledgments. We thank Professor P. J. J. Sauer for helpful suggestions and critical reading of the manuscript. We extend our appreciation to the parents and infants who volunteered their time to take part in this study.

\section{REFERENCES}

1. Kabir N, Forsum E 1993 Estimation of total body fat and subcutaneous adipose tissue in full-term infants less than 3 months old. Pediatr Res 34:448-454

2. Sheng HP, Muthappa PB, Wong WW, Schanler RJ 1993 Pitfalls of body fat assessments in premature infants by anthropometry. Biol Neonate 64:279-286

3. Davies PSW, Lucas A 1990 The prediction of total body fatncss in early infancy. Early Hum Dev 21:193-198

4. De Bruin NC, Van Velthoven CAM, Stijnen T, Juttmann RE, Degenhart HJ, Visser HKA Quantitative assessment of infant body fat by anthropometry and TOBEC. Am J Clin Nutr 61:279-286

5. Trowbridge FL, Graham GG, Wong WW, Mellits ED, Rabold JD, Lee LS, Cabrera MP, Klcin PD 1984 Body water measurements in premature and older infants using $\mathrm{H}_{2}{ }^{18} \mathrm{O}$ isotopic determinations. Pediatr Res 18:524-527

6. Fjeld CR, Freundt-Thurne J, Schocller DA 1990 Total body water measured by ${ }^{18} \mathrm{O}$ dilution and bioelectrical impedance in well and malnourished children. Pediatr Res 27:98-102

7. Fiorotto ML, Cochran WJ, Klish WJ 1987 Fat-free mass and total body water of infants estimated from total body electrical conductivity measurements. Pediatr Res $22: 417-421$
8. Fiorotto ML 1991 Measurements of total body electrical conductivity for the estimation of fat and fat-free mass. In: Whitehead RG, Prentice A (eds) New Techniques in Nutritional Research. Academic Press, San Diego, CA, pp 281--301

9. De Bruin NC, van den Berg, R, Degenhart HJ, and Visser HKA 1992 TOBEC, a good predictor of fat frce mass and body fat: Instrument calibration with minipigs by carcass analysis and $\mathrm{D}_{2} \mathrm{O}$ dilution. In: Proceedings of the 33rd Dutch Federation Meeting, Nijmegen: Federation of Medical Scientific Societies, p 54(abstr)

10. De Bruin NC, Luijendijk IHT, Visser HKA, Degenhart HJ 1994 Effect of alterations in physical and chemical characteristics on TOBEC-derived body composition estimates: Validation with non-human models. Phys Med Biol 39:1143-1156

11. Harker, WH (Inventor), EMME (Assignee) 1973 Method and apparatus for measuring fat content in animal tissue either in vivo or in slaughtered prepared form. US Patent $3,735,247$, May 22

12. Fiorotto ML, De Bruin NC, Brans YW, Degenhart HJ, Visser HKA 1995 Total body electrical conductivity measurements: An evaluation of current instrumentation for infants. Pediatr Res 37:94-100

13. De Bruin NC, Van Velthoven CAM, Brugman R, Degenhart HJ, Visser HKA 1994 Measuring body fat in infancy: anthropometry versus total body electrical conductivity (TOBEC). Pediatr Res 35:268(abstr)

14. Fomon SJ, Haschke F, Ziegler EE, Nelson SE 1982 Body composition of reference children from birth to age 10 years. Am I Clin Nutr 35:1169-1175

15. Fiorotto ML, Cochran WJ, Funk RC, Sheng HP, Klish WJ 1987 Total body electrical conductivity measurements: Effects of body composition and geometry. Am. J Physiol 252:R794-R800

16. Cochran WJ, Fiorotto ML, Sheng HP, Klish WJ 1989 Reliability of fat-free mass estimates derived from total-body electrical conductivity measurements as influenced by changes in extracellular fluid volume. Am J Clin Nutr 49:29-32

17. Coward A 1990 Calculation of pool sizes and flux rates. In Prentice AM (ed) The Doubly-Labelled Water Method for Measuring Energy Expenditure. Technical Recommendations for use in Humans. International Atomic Energy Agency, Vienna, pp $48-68$

18. Lohman TG, Roche AF, Martorell R 1988 Anthropometric Standardization Reference Manual. Human Kinetic Books, Champaign, IL

19. EM-SCAN Inc. 1989 Operator's Manual. Springfield, IL

20. Whyte RK, Bayley HS, Schwarcz HP 1985 The measurement of whole body water by $\mathrm{H}_{2}{ }^{18} \mathrm{O}$ dilution in newborn pigs. Am $\mathrm{J}$ Clin Nutr 41:801-809

21. Westerterp KR, Brouns F, Saris WHM, Ten Hoor F 1988 Comparison of doublylabeled water with respirometry at low- and high-activity levels. J Appl Physiol 65:53-56

22. Schoeller DA, Ravussin E, Schutz Y, Acheson KJ, Baertschi P, Jéquier E 1986 Energy expenditure by doubly labeled water: Validation in humans and proposed calculation. Am J Physiol 250:R823-R830

23. Schoeller DA, Van Santen E, Petersen DW, Dietz W, Jaspan J, Klein PD 1980 Total body water measurement in humans with ${ }^{18} \mathrm{O}$ and ${ }^{2} \mathrm{H}$ labeled water. Am $\mathrm{J}$ Clin Nutr 33:2686-2693

24. Draper N, Smith H 1981 Applied Regression Analysis, 2nd Ed. J. Wiley \& Sons, New York, Chap 1

25. Bland JM, Altman DG 1986 Statistical methods for assessing agreement between two methods of clinical measurement. Lancet 1:307-310

26. Roede MJ, Van Wieringen JC 1985 Growth diagrams 1980. Netherlands third nation-wide survey. Tijdschr Soc Gezondheidszorg, 63(suppl)1-34

27. Westerterp KR, Lafeber HN, Sulkers EJ, Sauer PJJ. Comparison of short term indirect calorimetry and doubly labelled water method for the assessment of energy expenditure in pretcrm infants. Biol Neonatc 60:75-82

28. Jones PJH, Winthrop AL, Schoeller DA, Swyer PR, Filler RM, Heim $\Upsilon 1987$ Validation of doubly labeled water for assessing energy expenditure in infants. Pediatr Res 21:242-246

29. Jensen CL, Butte NF, Wong WW, Moon JK 1992 Determining energy expenditure in preterm infants: comparison of ${ }^{2} \mathrm{H}_{2}{ }^{18} \mathrm{O}$ method and indirect calorimetry. Am J Physiol 263:R685-R692

30. Ziegler EE, O'Donnell AM, Nelson SE, Fomon SJ 1976 Body composition of the reference fetus. Growth 40:329-341

31. Fomon SJ 1967 Body composition of the male reference infant during the first year of life. Borden Award Address, October 1966. Pediatrics 40:863-870

32. Widdowson EM, McCance RA, Spray CM 1951 The chemical composition of the human body. Clin Sci 10:113-125 